\title{
Understanding Effective Web Messaging - The Case of Menopause
}

\author{
Gillie Gabay ${ }^{1}$, Attila Gere ${ }^{2}$ and Howard Moskowitz ${ }^{3 *}$ \\ ${ }^{1}$ School of Behavioral Sciences and Psychology, College of Management Academic Studies, Israel. \\ ${ }^{2}$ Szent István University, Faculty of Food Science, Department of Postharvest Science and Sensory Evaluation, Budapest, Hungary \\ ${ }^{3}$ Mind Genomics Associates, Inc. White Plains, NY USA
}

*Corresponding author: Howard Moskowitz, Mind Genomics Associates, Inc. White Plains, NY USA; Email: mjihrmn@sprynet.com

Received: February 24, 2019; Accepted: February 27, 2019; Published: March 25, 2019;

\begin{abstract}
We present a study of messages 'scraped' from websites dealing with the topic of menopause. Through Mind Genomics it becomes straightforward to identify how each element drives interest. We show how to estimate the impact of untested elements. We finish with the demonstration that there are at least three dramatically different mind-sets, responding to different messages, along with a very large group of people who are indifferent to most messages. The different mind-sets can be identified by an easy-to-use and short Personal Viewpoint Identifier (PVI). The PVI provides the communicator with the opportunity to tailor the messages so that the correct message can be sent to each woman.
\end{abstract}

Keywords: Communication; Menopause; Messaging; Mindset-segmentation; Health-Marketing; Well-Being

\section{Introduction}

At the time of this writing, menopause remains a fact of life for women age 40 or older. The concern is not medical, but rather involves medical concerns. The focus of society on staying young and fit, coupled with the inevitable body changes which occur before and during menopause, causes, in its wake, a great deal of anxiety. The anxiety is manifested by the proliferation of websites dealing with menopause.

\section{Attitudes towards menopause and health promotion}

Menopause manifests itself in many ways. Symptoms of menopause include cardiac trouble, lack of drive, urological symptoms, sexual disturbances, vaginal dryness, joint and muscle symptoms, drop in performance, hot flashes, depression and agitation [1]. Some symptoms of menopause have been reported to be extremely common. Hot flushes and night sweats affect about $70 \%$ of European and American women and are the most common symptoms reported during menopause. These are not the only symptoms, and indeed the manifesting symptoms vary. Differences in symptoms are attributed to diet, body mass index, exercise and mood, as well as to attitudes towards menopause $[2,3]$.

There is more to menopause than the physical symptoms. There is the way the woman responds to the entire gestalt, including aging and the virtually impossible to 'cure' menopause. An attitude towards menopause is one's opinion or general feelings about the menopause' $[4,5]$. The reported literature does not present a clear picture of how attitudes co-vary with, and drive responses to menopause. One's menopause may be perceived as a medical condition or as a natural phenomenon with positive or negative social changes attributed to this transition [6].

Previous studies reported significant associations between attitudes and symptoms of menopause $[4,7]$. The data suggested that the negativity of one's attitude, the higher the symptoms frequency (i.e., such as irritability, sleeplessness, and headaches; [4]). A few cross-sectional studies reported no significant relationship between menopausal attitude and the severity of symptoms [8]. Furthermore, women with more negative attitudes prior to menopause report a higher frequency of hot flush reporting later on [4].Younger women and pre-menopausal women reported the most negative attitudes towards menopause.

Interventions to change cognitions regarding menopause may improve attitudes, and significantly reduce the perceived severity of physiological, psychological and social symptoms. Social support and education are associated with more positive attitudes. In contrast, depression is associated with both negative attitudes and menopausal symptoms [4]. The most frequent and bothersome symptoms reported are psychological and physical symptoms such as irritability, tiredness, depressed feelings, memory problems and aches and pains [4].

Understanding the specific attitudes towards pre-menopause and menopause might enable clinicians to affect the person's cognition of the entire trajectory of menopause, and if properly done, perhaps reduce the person's negative attitudes towards menopause. Reducing negative attitudes may reduce the perceived frequency and severity of symptoms, with the benefit to promote health and quality of life during menopause. This study focuses on attitudes towards menopause within the English-speaking culture, and specifically on the responses 
to messages about menopause that are found on the Internet, on web pages. This study, in English, represents a first attempt to understand the response to web-based messages. Researchers have recognized that a full understanding of menopause must encompass data from several culture, so one can consider this project a first step, albeit a wide-ranging first step $[1,4,9]$.

From other research both in consumer groups and across medical issues, there continues to emerge the realization that people are not alike. Marketers, of course, have known this for a half century or more, and have offered different products in the same category to satisfy these different groups, so-called consumer segments.

How then does the marketer uncover the messages which attract people when they read websites? The marketers know that they must have a clear 'call to action, ' but how does one move the reader to take action? Marketers believe that people in so-called segments respond to the same messages, and therefore the holy grail of marketing is to discover those segments. Methods such as geo-demographic analysis (WHO the person IS), or behavior analysis (WHAT does the person SEARCH for) are today's favorites. The former is known as psychographic analysis, assuming that people who have the same attitudes towards a topic will, of course, react to the same messages. The latter is known as behavioral segmentation. Behavioral segmentation has become increasing popular as the Internet has grown. The Internet, allowing the marketer to understand the topics for which a person searches, the websites that the person reaches, and the path of navigating through the website and onwards to other websites. In other words, to the marketer, the answer 'must be in there,' simply because the website seems to encapsulate wants, actions, and thus should yield motives through deeper analysis. Whether or not the deeper analyses actually provide a sense of 'motives' remains a question.

About three decades ago, author Moskowitz suggested a different approach, indeed one pre-dating the behavioral segmentation. The ingoing assumption of the approach, later to be named Mind Genomics $[10,11]$ was that the understanding of motivation might be more rapidly achieved through small experiments. These experiments present the respondent with combinations of messages of different types, all from the same topic area (e.g., menopause for the current paper.) The respondent's task is to rate the combination as a single offering. There is no way that the respondent can understand the underlying structure by which the messages or elements are combined. Thus, the respondent must react at almost an intuitive, 'gut level.' The statistical procedures within Mind Genomics deconstruct the response to these tested combinations, the vignettes, showing the contribution of each element or message to driving the response.

Mind Genomics applied to the problem of messaging in websites, has the potential to easily and quickly reveal messages which motivate the total panel, as well as the nature new, unexpected groups of ideas, mind-sets, and the groups of people to whom these groups of ideas appeal, as well as groups of people to whom the ideas fail to appeal, and may even repel. These mind-sets allow the marketer to better understand the respondent, and to improve the cogency of the message in the website. In this study we focus on messaging for menopause.

\section{Method}

The basic steps in our study of menopause using Mind Genomics begin with an analysis of what is being featured by 'scraping' the websites and end up with segmentation results to shown different mind-sets.

1. Create raw materials: The elements comprise both text phrases 'scraped' from websites dealing with menopause, as well as relevant pictures from the same set of websites. The websites are over a decade old; none of the specific material can be considered current. The fact that the material is not current is not relevant. As we will see, it is the nature of the messages which teach us a lot, as well as the discovery that most of the messages do not drive interest in the website, despite that the messages are about the topic, menopause. No, everything works, as we will soon demonstrate.

2. Select a workable number of elements, and, when necessary for clarity, edit the elements but keep their tonality: The elements include text elements as well as visual elements. In most cases the elements require a slight amount of editing to make sure that they can 'stand alone,' or be combined in messages with other elements.

3. Classify the elements: Mind Genomics requires that we place the elements into mutually compatible groups, and assign each element or message to one of the groups (silos.) The silos will be irrelevant for the analysis but will ensure that mutually contradictory elements never appear together. In a sense we can consider the classification task as akin to 'bookkeeping.' Table 1 presents the different elements, classified into silos.

4. Dimensionalize the elements: The objective here is to locate each element in a set of five dimensions, these dimensions being relevant to the elements. A small group of six individuals profiled each element on every one of the five dimensions. From the fivedimensional profile of each element, the Mind Genomics algorithm calculated the eight 'nearest neighbors' in the five-dimensional space. The distance between each pair of elements was defined as the Euclidean distance computed in five dimensions.

5. Invite panelists to participate, working with a company which specializes in internet-based studies: There are many of these panel providers world-wide. The respondents for this study were members of a panel provider specializing in internet-based studies (Open View, Inc. in Toronto, CA.) The panel provider sent out invitations which told the female respondents about a study, and the chance to win a sweepstakes prize. Those respondents who were members of the Open View panel and agreed to participate were led to the welcome page, shown in Figure 1.

6. Create the test vignettes (combinations of elements.): A test vignette comprised 25 combinations of elements. The Mind Genomics algorithm selected five silos, and four elements from each silo. The elements were combined into 25 vignettes, with the property that each vignette contained 2-4 elements, with a vignette comprising no more than one element from a silo, but often no element from the silo. The frequency of selection of each element 
was equal across all the respondents, although each respondent sampled only a small set (20 elements) of the much larger total. The Mind Genomics system ensured that the 20 elements in a design end up as statistically independent of each other, allowing later analysis by OLS (ordinary least-squares) regression. Figure 2 shows an example of a vignette

7. Design of the vignettes: Each experimental design selected a set of five silos, and a random four elements from each silo. From the selection of the 20 elements, the experimental design constructed 25 combinations with the property that the elements were statistically independent of each other. This was done twice, so each respondent ended up evaluating up to 40 different elements, arranged in a total of 50 combinations. Figure 2 shows an example of one of the combinations created by the design.

8. Respondent instruction: The respondent was instructed to read the vignette, who participated evaluated two sets of 25 vignettes each ( 50 vignettes in total), created according to a basic experimental design which was permuted [12]. Each respondent thus evaluated two unique sets of 25 vignettes each with the vignettes randomized.

9. Self-profiling classification: At the end of the experiment, approximately 15 minutes after the start, the respondent completed an additional classification questionnaire, which generated information about WHO the respondent is (age, market), MENOPAUSE-RELATED information, and other relevant information. Figure 3 shows one of the screens, which obtains information on the treatments that the respondent is using to treat menopause symptoms.

10. Transform the ratings to a binary scale to prepare for regression: One of the foundations of Mind Genomics is the creation of equations relating the presence/absence of the elements in the vignettes to the rating. The respondents assigned each of 50 vignettes a rating from 1 (not interested) to 9 (interested.) Most managers have a difficult time understanding the meaning of a 9-Point Likert Scale. Some managers want the scale to be labelled at every point to understand the scale. A more productive way to ensure understanding bifurcates the scale, so that ratings of 1-6 are assigned the value ' 0 ' and the ratings of 7-9 are assigned the value of ' 100 .' The final preparatory action is to add a small random number $\left(<10^{-5}\right)$ to each transformed value, so that the new dependent variables are not exactly 0 or 100 , but slight variations. The small random number does not materially affect the regression analysis but ensures that the regression model 'works.'

11. Create the model by regression: The underlying experimental design ensures that the 40 elements combined into the set of 50 vignettes are statistically independent of each other. The statistical independence allows the researcher to apply OLS (ordinary least squares regression). The equation is:

$$
\begin{gathered}
\text { Binary Rating }=\mathrm{k}_{0}+\mathrm{k}_{1}(\text { Element } \mathrm{A} 1)+\mathrm{k}_{2}(\text { Element A2 }) \ldots . \\
\mathrm{K}_{50}(\text { Element } \mathrm{J} 4)
\end{gathered}
$$

The equation shows that the binary rating can be expressed as an additive constant $\left(\mathrm{k}_{0}\right)$ and the weight contribution of the 40 elements, with sets of four drawn from a single silo or category. The Mind Genomics algorithm ensures that each element in the study appears an equal number of times. The vignettes comprise a minimum of two elements, and a maximum of five elements.

12. Estimate the coefficient of each untested elements for each respondent: In many of these studies, the desire is to create a complete model for respondent. The realities of times, however, especially with internet-based interviews, militates against large number of respondents spending as much as an hour or two on the internet. A more efficient way is to estimate the coefficients of untested elements. The approach is to profile each of the elements on a set of five semantic scales. The semantic scales allow us to define the distance between every pair of elements, using the standard Euclidean distance measure, albeit in five dimensions. Following this line of thought, we define the eight closest neighbors of every element, based on the Euclidean distances. For each respondent, we have those elements that we tested, and have coefficients. We put these into an order which is defined by their code number (the silo and the element in the silo.) We then proceed to estimate the coefficients of untested elements. We never change the coefficients of tested elements for a respondent. For the untested elements, we put in the starting value 0 . We then begin from the first element. When the first element had been tested, we skip to the next element, the second element. When that element was not tested, we replace its value (starting with 0 ) with the average coefficient of the eight 'closest neighbors.' We proceed to the third element, and so forth. We continue this process, going back to the first element. We stop when the value of each untested coefficient stops changing. 'Stops changing' is defined as the magnitude of change being less than 0.01 in either direction when it comes time for the coefficient of the untested element to be re-estimated. The process is fast, and quite conservative. It underestimates the coefficients of untested elements, but still shows differences among the elements.

The 552 respondents who participated generated results shown in Table 2. The table shows only a portion of the elements, those which generated a coefficient of 6 or higher, or a negative coefficient. The additive constant for interest in the web is 56 , meaning that the conditional probability is over $50 \%$ that this targeted audience will be interested in the website on menopause. The surprise, however, is that only a few of the elements perform well, and none perform with a coefficient of 8 or higher. We conclude from Table 2 that either the "typical respondent" is scarcely interested, or that we have different groups of respondents, and that there is no single element which performs very well across all subgroups of respondents. It is a tribute to the web developers that no element ended up with a strongly negative coefficient, however.

\section{Mind-Sets - the clue to more effective messaging}

The foregoing results for Total Panel (Table 2) and for relevant subgroups (Table 3) suggest that the conventional way of dividing respondents does not uncover very strong messages, with 'very strong' operationally defined here as a coefficient higher than 10.51 (rounding up to 11) or higher. There are NO elements which score 11 or higher, either for total panel or for the self-defined subgroups based upon the self-profiling classification. 
Howard Moskowitz (2019) Understanding Effective Web Messaging - The Case of Menopause

Table 1. The elements classified into silos

\begin{tabular}{|c|c|}
\hline & Silo FA - Facts about menopause \\
\hline FA01 & Menopause is a natural event in a woman's life \\
\hline FA02 & Smokers go through menopause two to three years earlier than their non-smoking peers \\
\hline FA03 & Menopause is established when menses have not occurred for a year \\
\hline FA04 & A hot flash lasts from 30 seconds to 5 minutes and may be followed by chills \\
\hline \multirow[t]{2}{*}{ FA05 } & Every woman is different \\
\hline & Silo GI - General Information \\
\hline GI01 & Sunburn will aggravate your hot flashes because burnt skin cannot regulate heat as effectively \\
\hline GI02 & Learn more about the effects of menopause on your health \\
\hline GI03 & Symptoms may last from a couple of years to eight years or more \\
\hline GI04 & Devoted to providing women with updated information \\
\hline GI05 & Several excellent reference books are for sale online \\
\hline GI06 & Early physical symptoms include hot flashes, night sweats and sleeplessness \\
\hline GI07 & Emotional problems at menopause include mood swings, crying spells and irritability \\
\hline GI08 & The average age at which menopause occurs is about 50 years \\
\hline GI09 & Estrogen replacement therapy can help prevent osteoporosis \\
\hline GI10 & Estrogen replacement therapy can help prevent atherosclerosis and coronary artery disease \\
\hline GI11 & Side effects of estrogen replacement therapy include nausea, breast discomfort, headache, and mood changes \\
\hline GI12 & Menopause may be natural, artificial, or premature \\
\hline GI13 & Estrogen replacement therapy...may prevent atherosclerosis and coronary artery disease \\
\hline GI14 & Estrogen may be given as a tablet or as a skin patch (transdermal estrogen) \\
\hline GI15 & Simple tests will accurately determine what's going on and what stage of menopause you're in \\
\hline GI16 & Progesterone is taken with estrogen to reduce the risk of endometrial cancer \\
\hline GI17 & Commonly, estrogen and progesterone are taken everyday \\
\hline GI18 & Don't expect changes overnight \\
\hline GI19 & Hooking up with women in a menopause support group can really help \\
\hline GI20 & Women often experience many of the symptoms of menopause long before they have skipped a period \\
\hline GI21 & Experiencing hot flashes or insomnia can occur ten years before the last menstrual period \\
\hline GI22 & Menopause support groups can help \\
\hline GI23 & Mood swings can often accompany menopause \\
\hline \multirow[t]{2}{*}{ GI24 } & Share your experience with other women \\
\hline & Silo LC - Life changes to ameliorate symptoms and to feel healthier \\
\hline LC01 & If you smoke, cut down or quit \\
\hline LC02 & Avoid "trigger" foods such as caffeine, alcohol, spicy food, and sugar \\
\hline LC03 & Substitute coffee or regular tea for herbal teas \\
\hline LC04 & Exercise to improve your circulation \\
\hline LC05 & Reduce your exposure to the sun \\
\hline LC06 & Avoiding caffeine and alcohol can ease menopausal symptoms \\
\hline LC07 & Eating more fruits, vegetable and grain products while avoiding red meat and fat is even more important during menopause \\
\hline LC08 & Monitoring intake of fat, calcium, and vitamins can help treat problems associated with menopause \\
\hline LC09 & Dietary changes such as the supplement of soy foods may also help increase levels of estrogen \\
\hline LC10 & $\begin{array}{l}\text { Actions you take can save your bones, protect your heart, preserve your sex life, improve your memory and allow you to live longer and } \\
\text { happier }\end{array}$ \\
\hline LC11 & Getting enough calcium is important \\
\hline
\end{tabular}


Howard Moskowitz (2019) Understanding Effective Web Messaging - The Case of Menopause

\begin{tabular}{|c|c|}
\hline LC12 & A healthier lifestyle has to become a lifelong habit \\
\hline LC13 & Avoid spicy foods, alcohol and caffeine \\
\hline LC14 & With proper care and attention, we can all reach what Margaret Mead called a state of "post menopausal zest" \\
\hline LC15 & Menopause is a time for reassessment of our lives and health habits \\
\hline LC16 & Make as many healthy lifestyle changes as you can \\
\hline \multirow[t]{2}{*}{ LC17 } & Tell your friends and family what's going on \\
\hline & Silo MP - Medical practice considerations \\
\hline MP01 & Discuss with your doctor the benefits of taking vitamin $\mathrm{E}$ supplements \\
\hline MP02 & Visit your gynecologist annually or semiannually \\
\hline MP03 & Ask questions and express your concerns \\
\hline MP04 & Review your health status with your doctor regularly \\
\hline MP05 & Discuss treatment side effects with your doctor \\
\hline MP06 & Prevent osteoporosis after menopause \\
\hline MP07 & Always consult your own doctor about any opinions or recommendations \\
\hline MP08 & Talk to your doctor to see what is right for you \\
\hline MP09 & Learning about all of the options will help you and your doctor make the best decisions for your care \\
\hline MP10 & Talk with your doctor about other methods or dosages \\
\hline MP11 & Inform your doctor of any personal and family medical changes \\
\hline MP12 & Have an annual physical examination, along with a pelvic exam, Pap smear and breast exam \\
\hline MP13 & Receive a yearly mammogram (breast $\mathrm{x}$-ray) \\
\hline MP14 & Perform a breast self-exam each month \\
\hline MP15 & Report any abnormal vaginal bleeding \\
\hline MP16 & Have a yearly endometrial biopsy \\
\hline MP17 & Check blood pressure as often as your doctor suggests \\
\hline MP18 & Check your cholesterol before you start therapy \\
\hline MP19 & Ask for the lowest dose of estrogen to control symptoms \\
\hline MP20 & Review dosage levels of your hormone replacement therapy with your doctor periodically \\
\hline MP21 & Talk with your doctor about the risks and benefits of each type of treatment \\
\hline MP22 & Weigh the risks and benefits of hormone replacement therapy carefully with your doctor \\
\hline MP23 & Estrogen supplements are best known for preventing and treating osteoporosis \\
\hline MP24 & It's important to have a complete medical history and physical examination taken \\
\hline \multirow[t]{2}{*}{ MP25 } & Never be afraid to ask your doctor questions! \\
\hline & Silo NR - Natural products and practices \\
\hline NR01 & Soy products contain high levels of plant estrogens (phytoestrogens) \\
\hline NR02 & Natural hormones are produced from plants and come in cream or pill form \\
\hline NR03 & Learn about natural therapies and hormone preparations \\
\hline NR04 & Naturopathic medicine uses herbs \\
\hline NR05 & Naturopathic medicine uses acupuncture \\
\hline NR06 & Many natural treatments are available \\
\hline NR07 & Homeopathic medicines can be helpful \\
\hline NR08 & Only very low doses of a natural estrogen are needed to prevent hot flashes and osteoporosis \\
\hline NR09 & Soy supplements are being marketed to women as hot flash cure-alls \\
\hline NR10 & Trying herbs on your own can be risky \\
\hline NR11 & Many women find natural and herbal remedies to be helpful \\
\hline
\end{tabular}


Howard Moskowitz (2019) Understanding Effective Web Messaging - The Case of Menopause

\begin{tabular}{|c|c|}
\hline NR12 & The most popular remedy to relieve symptoms associated with menopause is soy supplementation \\
\hline \multirow[t]{2}{*}{ NR13 } & Many remedies are available for hot flashes \\
\hline & Silo SR - Alleviating symptoms by specific products \\
\hline SR01 & Reduce the undesirable symptoms of menopause \\
\hline SR02 & Menopause symptoms can be treated by hormone replacement therapy \\
\hline SR03 & Know how to manage the symptoms...have a plan to stay healthy in the years ahead \\
\hline SR04 & Herbs can help some of the symptoms of menopause \\
\hline SR05 & Vitamins in higher than usual doses can help some of the symptoms of menopause \\
\hline SR06 & Herbal therapy may relieve some of the common discomforts associated with menopause \\
\hline SR07 & Herbs can alleviate some of the symptoms in some women \\
\hline SR08 & Soy isoflavones may help alleviate the symptoms of menopause \\
\hline SR09 & Regular physical exercise will help prevent or relieve many of the common discomforts of menopause \\
\hline SR10 & Symptoms are treated by restoring estrogen to premenopausal levels \\
\hline SR11 & The primary goals of estrogen replacement therapy are: relief of symptoms such as hot flashes, vaginal dryness, and urinary problems \\
\hline SR12 & Estrogen replacement therapy relieves hot flashes \\
\hline \multirow[t]{2}{*}{ SR13 } & Exercise can be beneficial for symptom relief \\
\hline & Silo TT - Hormonal, herbal, nutritional remedies \\
\hline TT01 & Talk to your doctor about whether you should receive postmenopausal hormone therapy \\
\hline TT02 & Consider taking a combination therapy that uses estrogen and progestin \\
\hline TT03 & Be alert for side effects from any treatment, including hormone therapy \\
\hline TT04 & Hormone therapy lowers cholesterol \\
\hline TT05 & Women are seeking herbal and nutritional therapies to ease hot flashes and other symptoms of menopause \\
\hline TT06 & Many herbal remedies may help ease some discomforts \\
\hline TT07 & Doctors feel comfortable recommending herbal or nutritional therapies for symptoms of menopause \\
\hline TT08 & Hormone replacement therapy has significant benefits in reducing the rapid bone loss that accompanies menopause \\
\hline ТT09 & Hormone replacement therapy can help a woman reduce her risk for osteoporosis \\
\hline TT10 & Talk to your doctor about all the available options...decide which is best for you \\
\hline TT11 & Hormone replacement therapy helps preserve bone health \\
\hline TT12 & Traditional treatments... hormone replacement therapy...it all depends on YOU \\
\hline TT13 & A woman and her doctor must weigh the benefits against the risks before deciding whether to use estrogen replacement therapy \\
\hline TT14 & Find the right hormone combination for you \\
\hline TT15 & Estrogen replacement therapy may be appropriate for you \\
\hline TT16 & Many women feel better with estrogen treatment \\
\hline \multirow[t]{2}{*}{ TT17 } & Reassess your estrogen replacement therapy periodically \\
\hline & Silo VI - Visual \\
\hline VI01 & mindbody.gif \\
\hline VI02 & woman on the move.jpg \\
\hline VI03 & woman eating salad.jpg \\
\hline VI04 & woman with daughters.jpg \\
\hline VI05 & couple walking in woods.jpg \\
\hline VI06 & women jogging.jpg \\
\hline VI07 & woman at breakfast table.jpg \\
\hline VI08 & woman outdoors.jpg \\
\hline
\end{tabular}




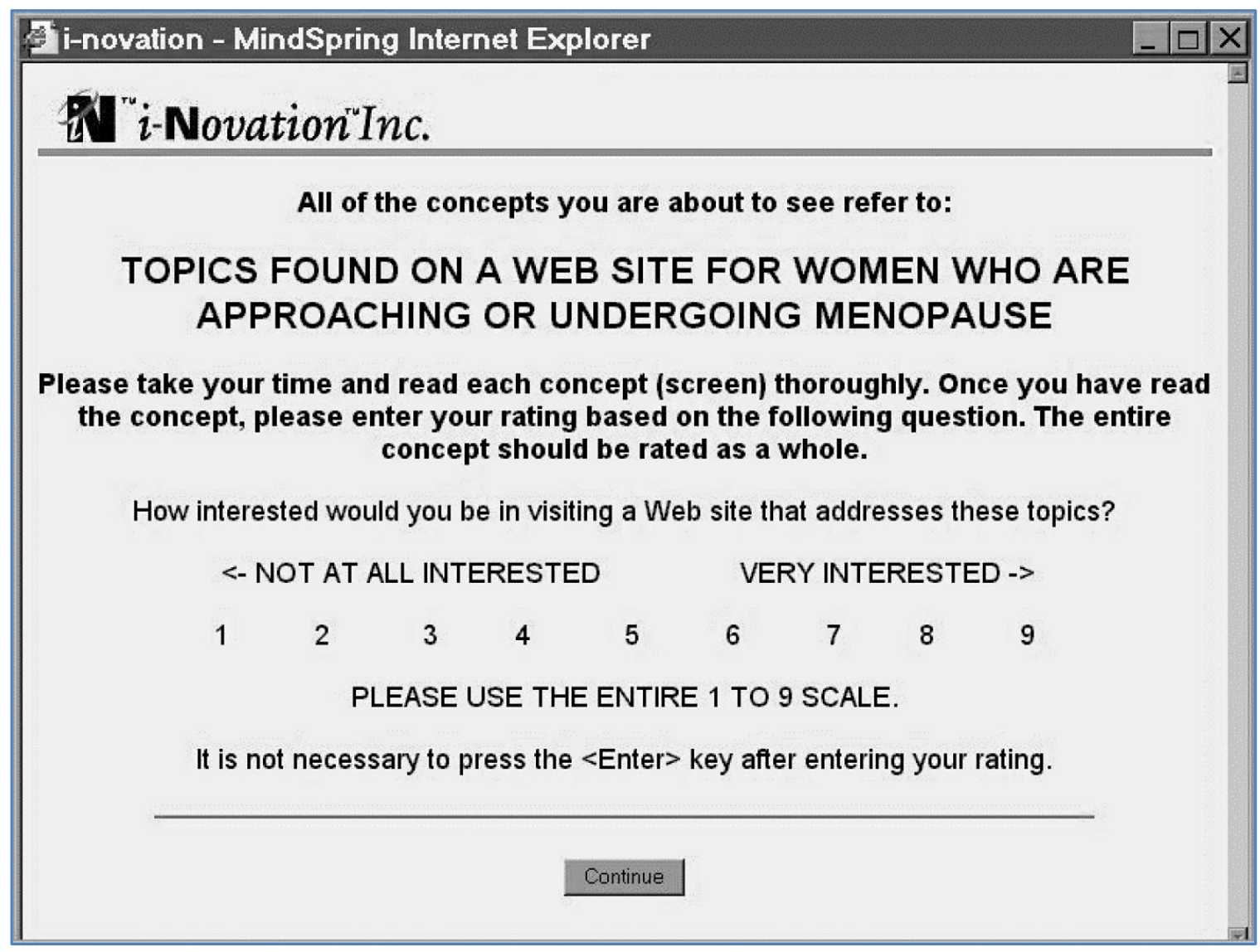

Figure 1. Welcome page for the menopause study.

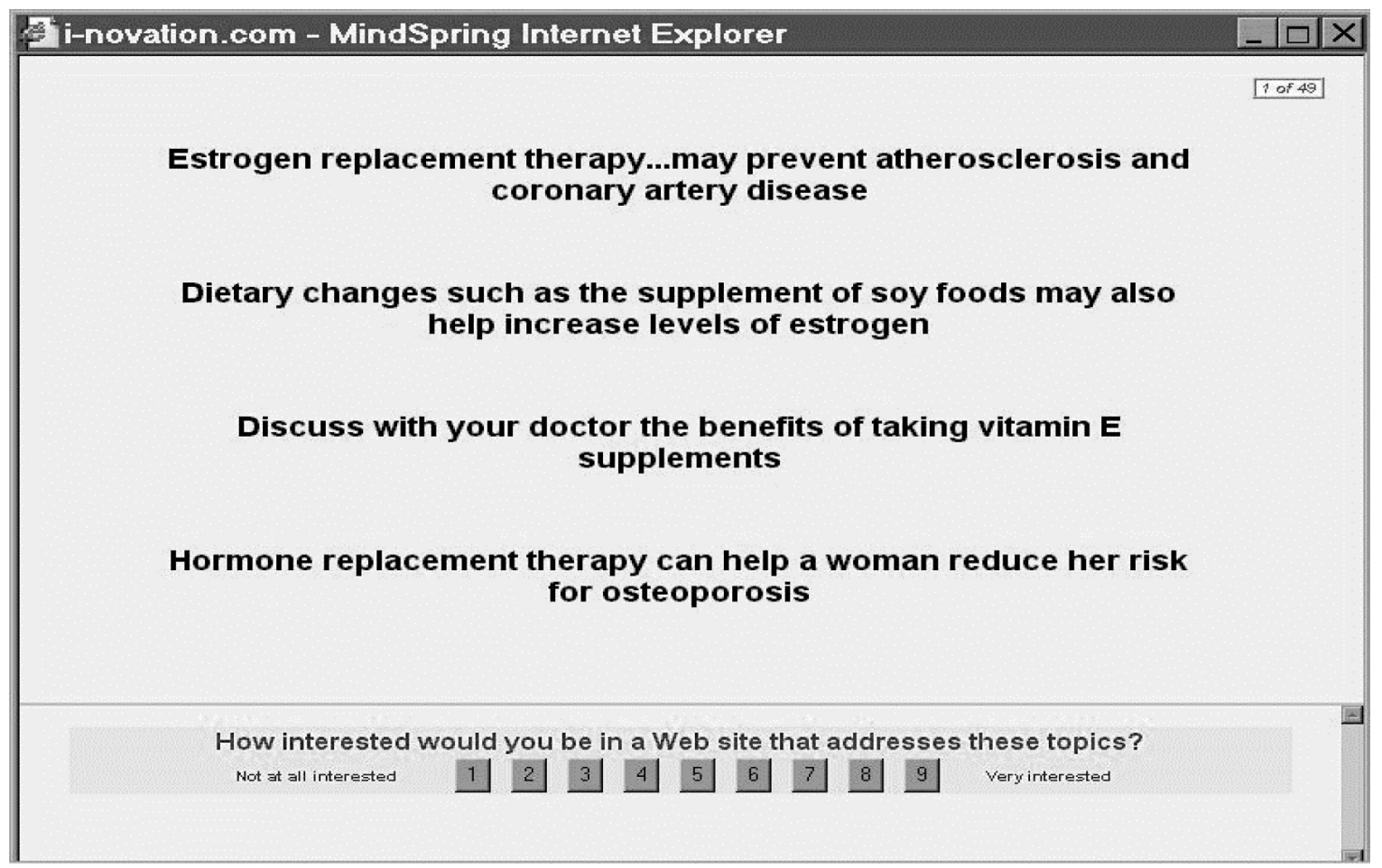

Figure 2. Example of a vignette created by the Mind Genomics system. 


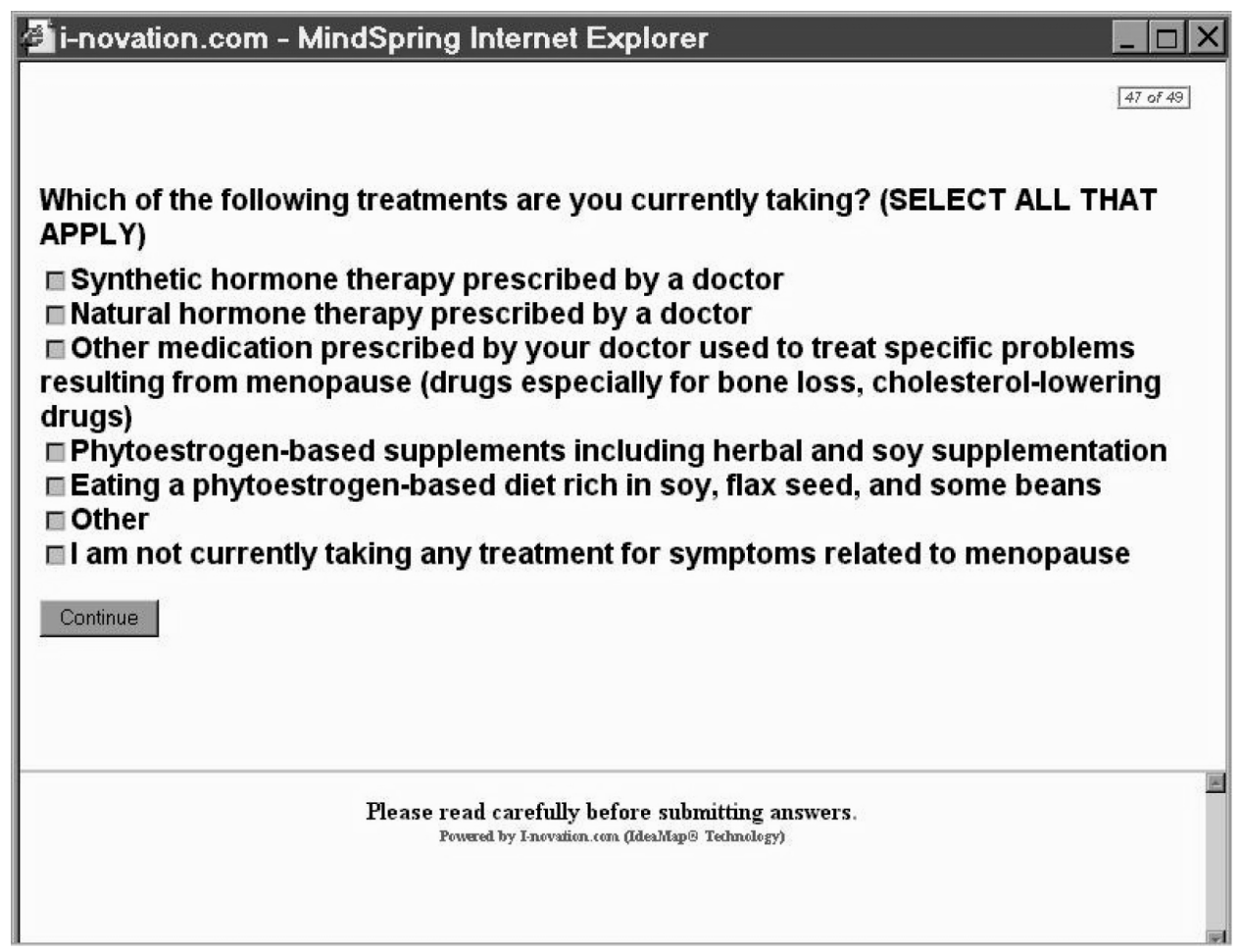

Figure 3. One of the screens for the self-profiling questionnaire, completed after the respondent completed the evaluation of the 50 experimentally varied vignettes. This screen deals with the treatments that the respondent is using to treat symptoms of menopause.

Table 2. The strong performing elements, defined as having a coefficient above 6 . The results come from the Total Panel of 552 respondents.

\begin{tabular}{|c|c|c|}
\hline & Additive constant for the total panel of 552 respondents & 56 \\
\hline MP1 & $\begin{array}{l}\text { Discuss with your doctor the benefits of taking vitamin E } \\
\text { supplements }\end{array}$ & 7 \\
\hline GI15 & $\begin{array}{l}\text { Simple tests will accurately determine what's going on and } \\
\text { what stage of menopause you're in }\end{array}$ & 7 \\
\hline LC10 & $\begin{array}{l}\text { Actions you take can save your bones, protect your heart, } \\
\text { preserve your sex life, improve your memory and allow you to } \\
\text { live longer and happier }\end{array}$ & 7 \\
\hline NR11 & Many women find natural and herbal remedies to be helpful & 6 \\
\hline GI6 & $\begin{array}{l}\text { Early physical symptoms include hot flashes, night sweats and } \\
\text { sleeplessness }\end{array}$ & 6 \\
\hline TT5 & $\begin{array}{l}\text { Women are seeking herbal and nutritional therapies to ease hot } \\
\text { flashes and other symptoms of menopause }\end{array}$ & 6 \\
\hline SR6 & $\begin{array}{l}\text { Herbal therapy may relieve some of the common discomforts } \\
\text { associated with menopause }\end{array}$ & 6 \\
\hline TT10 & $\begin{array}{l}\text { Talk to your doctor about all the available options...decide } \\
\text { which is best for you }\end{array}$ & 6 \\
\hline GI4 & Devoted to providing women with updated information & 6 \\
\hline NR10 & Trying herbs on your own can be risky & 6 \\
\hline GI19 & $\begin{array}{l}\text { Hooking up with women in a menopause support group can } \\
\text { really help }\end{array}$ & 1 \\
\hline
\end{tabular}

Strong performing elements by key subgroup

We can sort the data into the different groups based on a variety of characteristics. Table 3 shows the strong performing elements for the different ages, self-reported progress toward menopause, and respondents who have various symptoms. Only elements performing well in at least one subgroup are shown. To avoid a 'wall of numbers' we have operationally defined the value of 8 as the low value of the coefficient that we will accept.
The answer to strong performing elements may lie in another way of thinking about respondents, not so much as people, but as a storage bin for a mind-set. In turn, a mind-set comprises a group of related ideas. The respondent is merely a protoplasmic-vehicle which holds these related ideas, and through testing allows these mind-sets to emerge. It is not the people, but the set of ideas which is the real essence of the mind-set: The foregoing distinction between the ideas and the people who hold these ideas, two different entities, emblemizes the difference between the way one thinks in general (measure the people, count the different opinions, tabulate), and the way one thinks with Mind Genomics (identify the mind-sets, and determine the distribution of these mind-sets in different populations.)

Uncovering mind-sets occurs through the statistical procedure of clustering. Each respondent generates a set of coefficients, one coefficient for each element, along with an additive constant. The set of coefficients emerge from measuring the coefficients of elements tested by the respondent, and then imputing the values for elements untested by the respondent. The imputation was described above in the section on estimating the coefficients of untested elements.

Clustering attempts to separate the elements, i.e., the respondents, into different, non-overlapping groups. The mathematics is based upon the minimization of distances between respondents within a cluster, and then maximizing the differences between the centroids of different clusters. Each respondent generated one coefficient per element, whether that coefficient was from an actually-tested element, or whose value was imputed for the respondent because the respondent did not actually test the element since the element never appeared in any of the respondent's 50 vignettes. 
Table 3. Strong performing elements for different subgroups, defined by age, stage of menopause, and symptoms reported

\begin{tabular}{|c|c|c|c|c|c|c|c|c|c|c|c|c|c|}
\hline & & $\begin{array}{l}\vec{c} \\
\text { og } \\
\overrightarrow{0} \\
\vec{t}\end{array}$ & 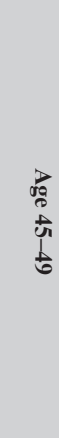 & $\begin{array}{l}\overrightarrow{0} \\
\text { og } \\
\text { 岁 } \\
\text { Un }\end{array}$ & 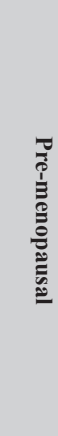 & 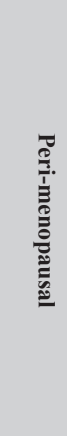 & 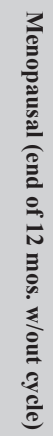 & 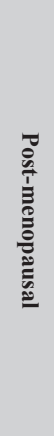 & 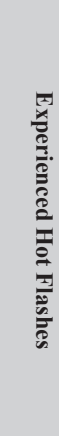 & 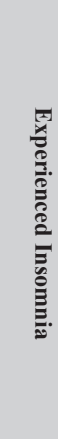 & 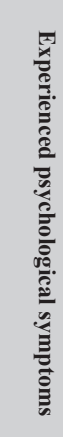 & 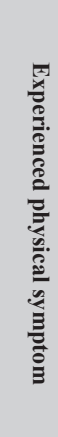 & 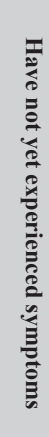 \\
\hline & Base size & 209 & 197 & 146 & 132 & 227 & 96 & 97 & 104 & 105 & 113 & 180 & 49 \\
\hline & Additive constant & 55 & 59 & 53 & 55 & 55 & 60 & 55 & 59 & 66 & 61 & 49 & 40 \\
\hline GI15 & $\begin{array}{l}\text { Simple tests will accurately determine what's going on and } \\
\text { what stage of menopause you're in }\end{array}$ & 8 & 8 & 7 & 7 & 8 & 8 & 7 & 6 & 7 & 9 & 7 & 9 \\
\hline LC10 & $\begin{array}{l}\text { Actions you take can save your bones, protect your heart, } \\
\text { preserve your sex life, improve your memory and allow you to } \\
\text { live longer and happier }\end{array}$ & 5 & 7 & 8 & 6 & 7 & 7 & 7 & 5 & 5 & 7 & 7 & 9 \\
\hline SR6 & $\begin{array}{l}\text { Vitamins in higher than usual doses can help some of the } \\
\text { symptoms of menopause }\end{array}$ & 6 & 6 & 8 & 7 & 6 & 4 & 8 & 2 & 6 & 8 & 8 & 4 \\
\hline GI4 & Devoted to providing women with updated information & 5 & 7 & 7 & 4 & 5 & 8 & 8 & 7 & 5 & 7 & 7 & 4 \\
\hline TT5 & Hormone therapy lowers cholesterol & 5 & 6 & 7 & 5 & 5 & 7 & 6 & 4 & 4 & 8 & 7 & 3 \\
\hline GI6 & $\begin{array}{l}\text { Early physical symptoms include hot flashes, night sweats and } \\
\text { sleeplessness }\end{array}$ & 5 & 6 & 6 & 6 & 5 & 2 & 10 & 3 & 7 & 6 & 6 & 8 \\
\hline TT10 & $\begin{array}{l}\text { Talk to your doctor about whether you should receive post- } \\
\text { menopausal hormone therapy }\end{array}$ & 4 & 6 & 7 & 5 & 5 & 7 & 7 & 3 & 4 & 8 & 6 & 6 \\
\hline NR11 & Trying herbs on your own can be risky & 4 & 5 & 7 & 3 & 6 & 5 & 7 & 3 & 4 & 8 & 8 & 1 \\
\hline TT7 & Many herbal remedies may help ease some discomforts & 5 & 5 & 6 & 7 & 5 & 3 & 6 & 0 & 3 & 9 & 6 & 7 \\
\hline TT12 & Hormone replacement therapy helps preserve bone health & 5 & 4 & 6 & 6 & 4 & 4 & 6 & 3 & 2 & 10 & 6 & 2 \\
\hline MP9 & Talk to your doctor to see what is right for you & 4 & 6 & 5 & 7 & 4 & 6 & 2 & 1 & 4 & 5 & 6 & 9 \\
\hline SR4 & $\begin{array}{l}\text { Know how to manage the symptoms...have a plan to stay } \\
\text { healthy in the years ahead }\end{array}$ & 4 & 5 & 5 & 6 & 4 & 4 & 6 & 3 & 4 & 7 & 5 & 8 \\
\hline SR1 & $\begin{array}{l}\text { Soy supplements are being marketed to women as hot flash } \\
\text { cure-alls }\end{array}$ & 5 & 6 & 4 & 4 & 5 & 3 & 8 & 0 & 5 & 7 & 6 & 4 \\
\hline MP24 & $\begin{array}{l}\text { Estrogen supplements are best known for preventing and } \\
\text { treating osteoporosis }\end{array}$ & 5 & 5 & 5 & 4 & 4 & 9 & 3 & 5 & 4 & 6 & 5 & 1 \\
\hline FA4 & $\begin{array}{l}\text { A hot flash lasts from } 30 \text { seconds to } 5 \text { minutes and may be } \\
\text { followed by chills }\end{array}$ & 5 & 5 & 3 & 7 & 4 & 2 & 6 & 1 & 5 & 5 & 5 & 8 \\
\hline GI11 & $\begin{array}{l}\text { Side effects of estrogen replacement therapy include nausea, } \\
\text { breast discomfort, headache, and mood changes }\end{array}$ & 5 & 5 & 3 & 4 & 4 & 4 & 6 & 0 & 4 & 8 & 5 & 6 \\
\hline MP22 & $\begin{array}{l}\text { Talk with your doctor about the risks and benefits of each type } \\
\text { of treatment }\end{array}$ & 4 & 5 & 5 & 5 & 4 & 6 & 4 & 4 & 3 & 4 & 4 & 10 \\
\hline SR2 & Exercise can be beneficial for symptom relief & 4 & 5 & 4 & 3 & 4 & 6 & 5 & 3 & 8 & 5 & 3 & 4 \\
\hline NR3 & $\begin{array}{l}\text { Natural hormones are produced from plants and come in cream } \\
\text { or pill form }\end{array}$ & 3 & 5 & 6 & 6 & 4 & 3 & 4 & 2 & 1 & 5 & 6 & 8 \\
\hline NR2 & Many remedies are available for hot flashes & 5 & 5 & 3 & 6 & 4 & 6 & 2 & 0 & 2 & 6 & 6 & 8 \\
\hline FA1 & Menopause is a natural event in a woman's life & 3 & 4 & 6 & 4 & 5 & 5 & 2 & 3 & 4 & 2 & 8 & -1 \\
\hline
\end{tabular}




\begin{tabular}{|l|l|l|l|l|l|l|l|l|l|l|l|l|l|}
\hline NR12 & Many women find natural and herbal remedies to be helpful & 3 & 5 & 5 & 4 & 6 & 1 & 4 & -2 & 2 & $\mathbf{9}$ & 6 & 3 \\
\hline MP23 & $\begin{array}{l}\text { Weigh the risks and benefits of hormone replacement therapy } \\
\text { carefully with your doctor }\end{array}$ & 4 & 4 & 4 & 2 & 4 & 7 & 3 & 3 & 1 & $\mathbf{8}$ & 4 & 5 \\
\hline NR13 & $\begin{array}{l}\text { The most popular remedy to relieve symptoms associated with } \\
\text { menopause is soy supplementation }\end{array}$ & 4 & 5 & 2 & 4 & 3 & 4 & 6 & 1 & 2 & $\mathbf{8}$ & 4 & 3 \\
\hline NR8 & Homeopathic medicines can be helpful & 2 & 4 & 6 & 2 & 3 & $\mathbf{9}$ & 2 & 4 & 4 & 4 & 4 & 2 \\
\hline
\end{tabular}

The actual clustering algorithm is called $\mathrm{k}$-means clustering. The clustering program used by Mind Genomics can be considered as a heuristic to divide a population of objects (here people) in a smaller, non-overlapping set of groups, segments, or in our terminology, 'mind-sets.'

The specific algorithm is one of a family of related algorithms. We define the distance between two people as the value (1-Pearson R, Pearson Correlation.) We compute the Pearson correlation between the coefficients of two people, and then define the distance between those people as the value $1-\mathrm{R}$. When the Pearson correlation is 1.0, the distance is $0(1-1=0$.) A Pearson correlation of +1.0 means that the two sets of coefficients are perfectly aligned. It makes sense that the distance should be 0 . In contrast, when the Pearson correlation is -1 , the distance is $2.0(1--1=2$.) The negative correlation means that the two sets of coefficients travel in opposite directions. The respondents are most different from each other, and thus are separated by the greatest distance.

When we cluster the respondents to uncover mind-sets, we do so with at least two objectives:

1. Parsimony. The fewer the number of mind-sets emerging from the study, the better the segmentation in terms of mathematical 'elegance.' Furthermore, it is important to minimize the number of segments in order to make the application easier. The fewer the number of segments or mind-sets, the easier it will be to create separate strategies to communicate with these mind-sets.

2. Interpretability. Opposing the objective of parsimony is the objective is having the mind-sets very focused, very singleminded. The greater the number of mind-sets, the more likely it will be that the emergent mind-sets will be single-minded, albeit of smaller size.

The analysis of these data suggests that four segments, four emergent mind-sets, represent a good compromise. Table 4 shows the strongest performing elements from each segment. By strong performing we operationally define coefficients of 11 or higher as 'strong' performing. There is no hard and fast rule about what is 'strong, ' but when we work with large numbers of elements with imputation of values for untested elements, the likelihood of having elements of 11 or higher from the total panel is low. We can feel comfortable with this value of 11 as a signal of a relevant element.

The four segments are:

1. Mind-Set $1, \mathrm{n}=153$, Additive constant $=74$, No elements are strong

2. Mind-Set 2, $\mathrm{n}=141$, Additive constant $=53$, Menopause simply as a part of life
3. Mind-Set 3, $\mathrm{n}=141$, Additive constant $=45$, Takes supplements

4. Mind-Set 4, $\mathrm{n}=117$, Additive constant $=48$, Takes replacement therapy

Quite often in these studies there are mind-sets which do not respondent strongly to any individual elements. That does not mean that the mind-set is indifferent. For our 552 respondents, the first emergent mind-set comprises 153 individuals who at a basic level are very interested in a menopause website (additive constant $=74$ ), but no element strongly moves their basic interest beyond that very

\section{Finding these segments in the population}

It is clear from the results in Table 4 that the respondents in the mind-sets are far more likely to have a positive feeling to messages tuned to their particular mind-set. The world of modest-only performance is not a condemnation of those who create content, but rather a reflection of a bland world of messaging which conceals within it treasures. Although Mind-Set 1 has no elements to which it responds strongly, and although Mind-Set 2 has only three elements to which it responds strongly, Mind-Sets 3 and 4, respectively, respond in a remarkably strong way to selected messages, and indeed to quite a number of these messages. It will be those mind-sets who will respond to the appropriate messages.

The next questions which naturally arises is how does one discover these mind-sets in the population at large? We cannot force respondents to participate in a 30-minute test to determine the pattern of their responses. Rather, we must search for better ways. One might look at the other patterns of behavior and attitude self-reported by the respondents, shown in the Appendix to this paper. The patterns are quite similar across respondents in the four mind-sets, suggesting that any attempt to isolate the respondents by their self-reported responses, especially WHO THEY ARE, and WHAT THEY DO, is likely to fail.

A separate approach, pioneered by author Gere creates a small set of questions, based upon the patterns of coefficients the three mind-sets (Mind-Set 1\&2 combined, Mind-Set 3, Mind-Set 4, respectively.) The coefficients are selected so that their patterns maximally differentiate among pairs of mind-set segments. The result is an efficient set of six elements, based upon the elements, the elements phrased as questions to be answer by either NO or YES, or some similar binary response. A respondent is presented with the six questions. The pattern of responses dictates the assignment to the segment membership. The output can be either a short report to the respondent doing the typing, a record for one's medical record, or even the re-direction of the respondent to the appropriate web-site. Figure 4 shows the PVI (personal viewpoint identifier), and the three different response screens, the appropriate 
response screen either given back to the respondent and/or placed into the respondent's medical records. The linking to the typing tool is the following (as of February, 2019.) http://162.243.165.37:3838/

TT12/

Table 4. The four mind-sets for menopause. The elements are those which perform strongly for each mind-set. The number on the right is the coefficient.

\begin{tabular}{|c|c|c|}
\hline & Strong performing elements for each mind-set & Coeff \\
\hline & $\begin{array}{c}\text { Mind-Set } 1, n=153 \text {, Additive constant }=74, \text { Highly interested in a menopause- oriented website, but no elements move them beyond their basic } \\
\text { high interest }\end{array}$ & \\
\hline & Mind-Set 2, $n=141$, Additive constant $=53$, Menopause simply as a part of life & \\
\hline FA1 & Menopause is a natural event in a woman's life & 11 \\
\hline VI7 & woman at breakfast table.jpg & 11 \\
\hline \multirow[t]{2}{*}{ GI20 } & Women often experience many of the symptoms of menopause long before they have skipped a period & 11 \\
\hline & Mind-Set 3, n=141, Additive constant $=45$, Takes supplements & \\
\hline MP1 & Discuss with your doctor the benefits of taking vitamin E supplements & 15 \\
\hline LC10 & Actions you take can save your bones, protect your heart, preserve your sex life, improve your memory and allow you to live longer and happier & 15 \\
\hline SR6 & Herbal therapy may relieve some of the common discomforts associated with menopause & 14 \\
\hline NR10 & Trying herbs on your own can be risky & 13 \\
\hline NR1 & Soy products contain high levels of plant estrogens (phytoestrogens) & 13 \\
\hline GI4 & Devoted to providing women with updated information & 12 \\
\hline SR4 & Herbs can help some of the symptoms of menopause & 12 \\
\hline NR12 & The most popular remedy to relieve symptoms associated with menopause is soy supplementation & 12 \\
\hline GI15 & Simple tests will accurately determine what's going on and what stage of menopause you're in & 12 \\
\hline MP7 & Always consult your own doctor about any opinions or recommendations & 12 \\
\hline MP8 & Talk to your doctor to see what is right for you & 12 \\
\hline SR3 & Know how to manage the symptoms...have a plan to stay healthy in the years ahead & 12 \\
\hline MP9 & Learning about all of the options will help you and your doctor make the best decisions for your care & 12 \\
\hline SR13 & Exercise can be beneficial for symptom relief & 12 \\
\hline MP10 & Talk with your doctor about other methods or dosages & 12 \\
\hline TT5 & Women are seeking herbal and nutritional therapies to ease hot flashes and other symptoms of menopause & 11 \\
\hline TT10 & Talk to your doctor about all the available options...decide which is best for you & 11 \\
\hline TT7 & Doctors feel comfortable recommending herbal or nutritional therapies for symptoms of menopause & 11 \\
\hline GI2 & Learn more about the effects of menopause on your health & 11 \\
\hline \multirow[t]{2}{*}{ TT12 } & Traditional treatments...hormone replacement therapy...it all depends on YOU & 11 \\
\hline & Mind-Set 4, $n=117$, Additive constant $=48$, Takes replacement therapy & \\
\hline GI15 & Simple tests will accurately determine what's going on and what stage of menopause you're in & 20 \\
\hline SR10 & Symptoms are treated by restoring estrogen to premenopausal levels & 19 \\
\hline MP20 & Review dosage levels of your hormone replacement therapy with your doctor periodically & 19 \\
\hline SR12 & Estrogen replacement therapy relieves hot flashes & 19 \\
\hline TT16 & Many women feel better with estrogen treatment & 18 \\
\hline SR2 & Menopause symptoms can be treated by hormone replacement therapy & 18 \\
\hline MP19 & Ask for the lowest dose of estrogen to control symptoms & 18 \\
\hline SR11 & The primary goals of estrogen replacement therapy are: relief of symptoms such as hot flashes, vaginal dryness, and urinary problems & 18 \\
\hline
\end{tabular}




\begin{tabular}{|c|c|c|}
\hline TT2 & Consider taking a combination therapy that uses estrogen and progestin & 18 \\
\hline TT1 & Talk to your doctor about whether you should receive postmenopausal hormone therapy & 18 \\
\hline MP24 & It's important to have a complete medical history and physical examination taken & 17 \\
\hline MP22 & Weigh the risks and benefits of hormone replacement therapy carefully with your doctor & 17 \\
\hline TT3 & Be alert for side effects from any treatment, including hormone therapy & 17 \\
\hline LC8 & Monitoring intake of fat, calcium, and vitamins can help treat problems associated with menopause & 17 \\
\hline TT17 & Reassess your estrogen replacement therapy periodically & 17 \\
\hline TT9 & Hormone replacement therapy can help a woman reduce her risk for osteoporosis & 17 \\
\hline SR1 & Reduce the undesirable symptoms of menopause & 16 \\
\hline MP23 & Estrogen supplements are best known for preventing and treating osteoporosis & 16 \\
\hline GI13 & Estrogen replacement therapy...may prevent atherosclerosis and coronary artery disease & 16 \\
\hline MP6 & Prevent osteoporosis after menopause & 16 \\
\hline TT15 & Estrogen replacement therapy may be appropriate for you & 16 \\
\hline TT8 & Hormone replacement therapy has significant benefits in reducing the rapid bone loss that accompanies menopause & 16 \\
\hline MP5 & Discuss treatment side effects with your doctor & 15 \\
\hline MP13 & Receive a yearly mammogram (breast $\mathrm{x}$-ray) & 15 \\
\hline LC6 & Avoiding caffeine and alcohol can ease menopausal symptoms & 15 \\
\hline GI17 & Commonly, estrogen and progesterone are taken everyday & 15 \\
\hline GI11 & Side effects of estrogen replacement therapy include nausea, breast discomfort, headache, and mood changes & 14 \\
\hline $\mathrm{LC} 10$ & Actions you take can save your bones, protect your heart, preserve your sex life, improve your memory and allow you to live longer and happier & 13 \\
\hline MP10 & Talk with your doctor about other methods or dosages & 13 \\
\hline TT14 & Find the right hormone combination for you & 13 \\
\hline GI14 & Estrogen may be given as a tablet or as a skin patch (transdermal estrogen) & 13 \\
\hline SR13 & Exercise can be beneficial for symptom relief & 12 \\
\hline NR13 & Many remedies are available for hot flashes & 12 \\
\hline LC7 & Eating more fruits, vegetable and grain products while avoiding red meat and fat is even more important during menopause & 12 \\
\hline LC11 & Getting enough calcium is important & 12 \\
\hline TT11 & Hormone replacement therapy helps preserve bone health & 12 \\
\hline GI10 & Estrogen replacement therapy can help prevent atherosclerosis and coronary artery disease & 12 \\
\hline MP16 & Have a yearly endometrial biopsy & 12 \\
\hline MP1 & Discuss with your doctor the benefits of taking vitamin $\mathrm{E}$ supplements & 11 \\
\hline NR1 & Soy products contain high levels of plant estrogens (phytoestrogens) & 11 \\
\hline SR3 & Know how to manage the symptoms... have a plan to stay healthy in the years ahead & 11 \\
\hline LC9 & Dietary changes such as the supplement of soy foods may also help increase levels of estrogen & 11 \\
\hline MP21 & Talk with your doctor about the risks and benefits of each type of treatment & 11 \\
\hline MP12 & Have an annual physical examination, along with a pelvic exam, Pap smear and breast exam & 11 \\
\hline MP15 & Report any abnormal vaginal bleeding & 11 \\
\hline MP18 & Check your cholesterol before you start therapy & 11 \\
\hline MP14 & Perform a breast self-exam each month & 11 \\
\hline GI16 & Progesterone is taken with estrogen to reduce the risk of endometrial cancer & 11 \\
\hline
\end{tabular}




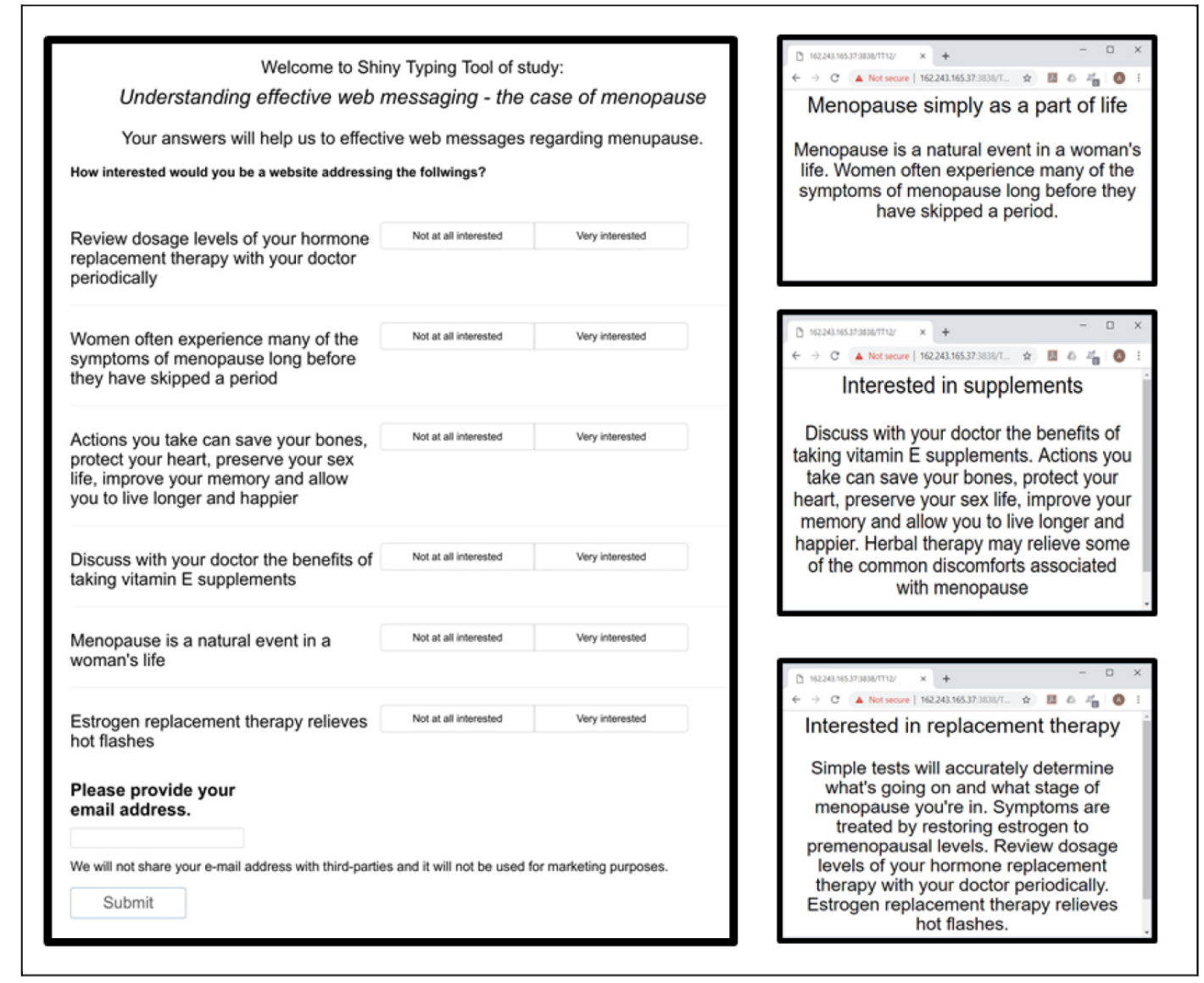

Figure 4. Personal Viewpoint Identifier (Left Panel), and the feedback screens (Right Panel)

\section{Discussion and Conclusion}

This study examines attitudes towards menopause within one culture. Attitudes towards menopause change by mindset-segment we uncovered in this study. Women in one major mindset-segment perceive menopause as part of life (original mind-sets 1 and 2). Women in the second major mindset-segment (original mind-set 3) perceive menopause as uncomfortable and take supplements to ease symptoms while reducing risk of taking hormone replacements. Women in the third mindset-segment (original mind-set 4) perceive menopause as a sign of old age and although they are aware of risks associates with hormone replacement, they take those to overcome the symptoms.

Echoing previous studies, menopause is indeed perceived sometimes as a medical condition and other times as a natural phenomenon with positive or negative physical and subsequent social changes attributed to this biological transition [6]. Our mindset- segments suggest a major mindset-segment of people who are aware of risks and take supplements rather than hormone therapy. Our psychographic mindset-segmentation contradicts previous findings that there exists a strong link between attitudes towards menopause and geode-demographic variables such as age, education, and social support [4]. The linkage is better conceptualized as mind-sets. It's more likely related to knowing HOW A PERSON THINKS ABOUT THE SPECIFIC TOPIC OF MENOPAUSE. Knowing mind-sets and tailoring messages to mind-sets (revealed for the individual through the PVI (personal viewpoint identifier) should dramatically increase the effectiveness of messages, and increase well-being and quality of life during menopause.

\section{Acknowledgement}

Attila Gere thanks the support of Premium Postdoctoral Researcher Program of Hungarian Academy of Sciences. 


\section{Appendix - Distribution of the four mind-sets of for menopause}

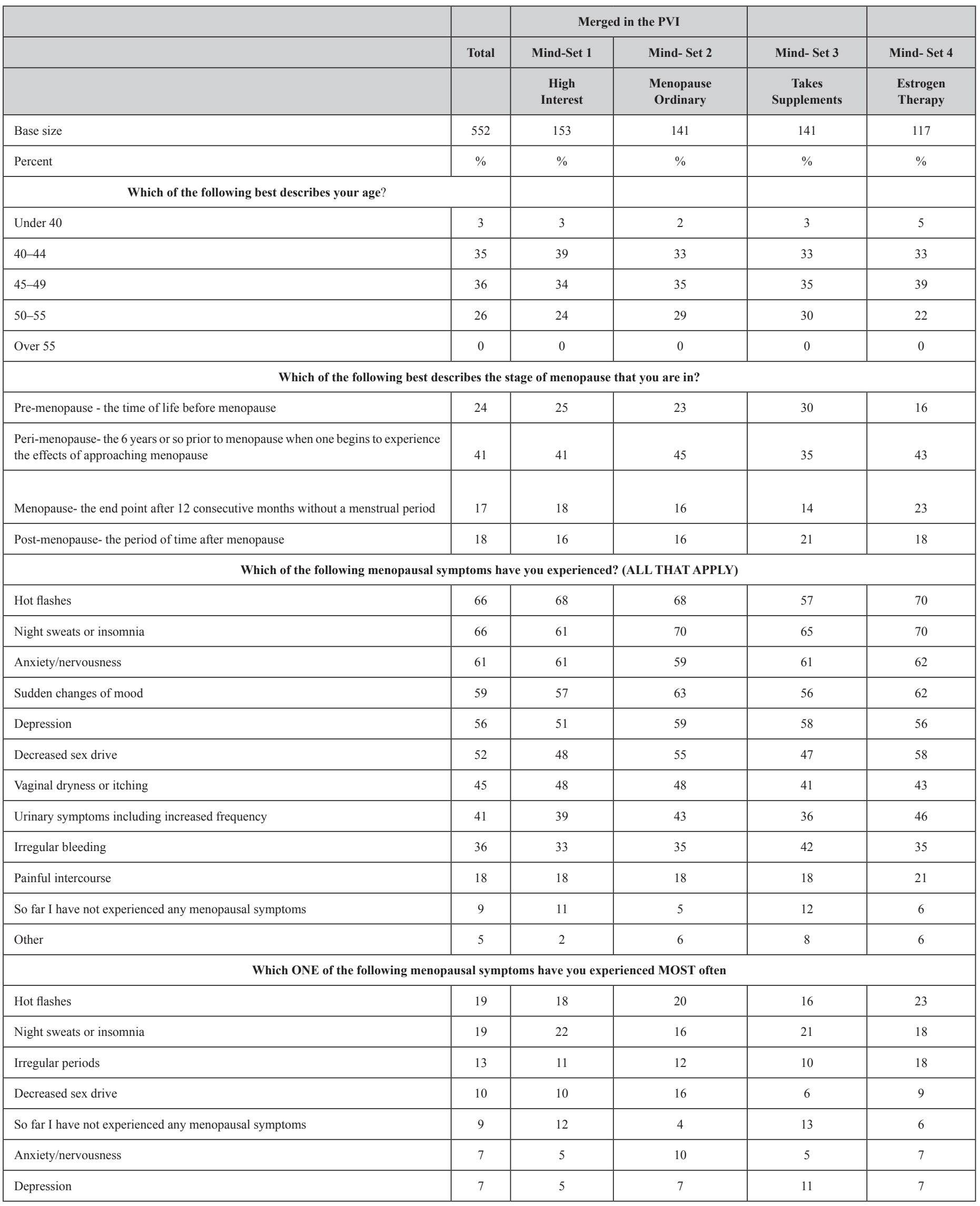




\begin{tabular}{|c|c|c|c|c|c|}
\hline Sudden changes of mood & 7 & 7 & 6 & 9 & 5 \\
\hline Vaginal dryness or itching & 5 & 6 & 5 & 6 & 4 \\
\hline Urinary symptoms including increased frequency & 4 & 6 & 4 & 3 & 2 \\
\hline Painful intercourse & 1 & 1 & 1 & 1 & 2 \\
\hline Other & 0 & 0 & 0 & 1 & 0 \\
\hline \multicolumn{6}{|c|}{ Which of the following issues associated with menopause are you concerned about? (T ALL THAT APPLY) } \\
\hline Osteoporosis or thinning of the bones & 59 & 55 & 59 & 60 & 65 \\
\hline Weight gain & 58 & 63 & 57 & 57 & 55 \\
\hline Getting enough calcium & 49 & 56 & 49 & 45 & 44 \\
\hline Risks associated with hormone replacement therapy & 48 & 53 & 45 & 48 & 46 \\
\hline Hormone replacement therapy & 47 & 53 & 38 & 48 & 46 \\
\hline Atherosclerosis and coronary artery disease & 45 & 50 & 35 & 46 & 48 \\
\hline Natural or alternative therapies & 44 & 45 & 49 & 43 & 38 \\
\hline Cancer & 42 & 47 & 34 & 44 & 44 \\
\hline Diet & 24 & 27 & 23 & 25 & 18 \\
\hline \multicolumn{6}{|c|}{ Which ONE of the following issues associated with menopause are you MOST concerned about? } \\
\hline Osteoporosis or thinning of the bones & 21 & 22 & 21 & 21 & 20 \\
\hline Weight gain & 16 & 13 & 17 & 18 & 15 \\
\hline Cancer & 15 & 17 & 11 & 14 & 17 \\
\hline Risks associated with hormone replacement therapy & 14 & 10 & 16 & 14 & 16 \\
\hline Atherosclerosis and coronary artery disease & 12 & 12 & 8 & 12 & 15 \\
\hline Natural or alternative therapies & 12 & 9 & 18 & 11 & 8 \\
\hline Hormone replacement therapy & 6 & 10 & 2 & 6 & 6 \\
\hline Getting enough Calcium & 5 & 7 & 6 & 4 & 3 \\
\hline Diet & 1 & $\mathbf{0}$ & 1 & 0 & 1 \\
\hline \multicolumn{6}{|c|}{ Which of the following treatments are you currently taking? (ALL THAT APPLY) } \\
\hline I am not currently taking any treatment for symptoms related to menopause & 67 & 66 & 72 & 65 & 67 \\
\hline Synthetic hormone therapy prescribed by a doctor & 20 & 20 & 18 & 18 & 23 \\
\hline $\begin{array}{l}\text { Other medication prescribed by your doctor used to treat specific problems resulting } \\
\text { from menopause (drugs especially for bone loss, cholesterol-lowering drugs) }\end{array}$ & 7 & 7 & 5 & 10 & 7 \\
\hline Phytoestrogen-based supplements including herbal and soy supplementation & 6 & 7 & 4 & 10 & 3 \\
\hline Natural hormone therapy prescribed by a doctor & 3 & 3 & 2 & 3 & 4 \\
\hline Eating a phytoestrogen-based diet rich in soy, flax seed, and some beans & 3 & 1 & 2 & 5 & 3 \\
\hline Other & 3 & 2 & 3 & 4 & 1 \\
\hline \multicolumn{6}{|c|}{ From which of the following sources do you obtain health related information? (ALL THAT APPLY) } \\
\hline Doctor & 77 & 78 & 78 & 69 & 84 \\
\hline Web sites/Internet & 73 & 70 & 77 & 74 & 70 \\
\hline Magazines & 52 & 55 & 50 & 52 & 50 \\
\hline Books & 47 & 46 & 38 & 58 & 47 \\
\hline
\end{tabular}




\begin{tabular}{|l|c|c|c|c|c|}
\hline Friends/Relatives & 43 & 40 & 48 & 43 & 44 \\
\hline Drug store/pharmacy & 37 & 37 & 37 & 30 & 47 \\
\hline TV & 35 & 33 & 32 & 41 & 35 \\
\hline Newspapers & 23 & 25 & 23 & 23 & 20 \\
\hline Other & 7 & 5 & 6 & 9 & 9 \\
\hline
\end{tabular}

\section{References}

1. Kowalcek I, Rotte D, Banz C, Diedrich K (2005) Women's attitude and perceptions towards menopause in different cultures. Cross-cultural and intra-cultural comparison of pre-menopausal and post-menopausal women in Germany and in Papua New Guinea. Maturitas 51: 227-235. [crossref]

2. Green R, Santoro N (2009) Menopausal symptoms and ethnicity: the Study of Women's Health Across the Nation. Womens Health (Lond) 5: 127-133. [crossref]

3. Santoro NF, Green R (2009) Menopausal symptoms and ethnicity: lessons from the Study of Women's Health Across the Nation. Menopausal Med 17: 6-8.

4. Ayers B, Forshaw M, Hunter MS (2010) The impact of attitudes towards the menopause on women's symptom experience: a systematic review. Maturitas 65: 28-36. [crossref]

5. Andrikoula M, Prelevic G (2009) Menopausal hot flushes revisited. Climacteric 12: 3-15. [crossref]

6. Avis NE, Crawford S (2008) Cultural differences in symptoms and attitudes toward menopause. Menopause Manage 17: 8-13.

7. Hunter MS, Gupta P, Papitsch-Clarke A, Sturdee D (2009) Mid-aged Health in Women from the Indian Subcontinent (MAHWIS): a quantitative and qualitative stud of experience of menopause in UK Asian women, compared to UK Caucasians and women living in Delhi. Climacteric 12: 26-37.

8. Akkuzu G, Orsal O, Kecialan R (2009) Women's attitudes towards menopause and influencing factors. Turkiya klinikleri J Med Sci 66-74.

9. Melby MK, Lock M, Kaufert P (2005) Culture and symptom reporting at menopause. Hum Reprod Update 11: 495-512. [crossref]

10. Moskowitz HR (2012) 'Mind genomics': the experimental, inductive science of the ordinary, and its application to aspects of food and feeding. Physiol Behav 107: 606-613. [crossref]

11. Moskowitz HR, Gofman A, Beckley J, Ashman H (2006) Founding a new science: Mind genomics. Journal of sensory studies 21: 266-307.

12. Gofman A, Moskowitz H (2010) Isomorphic permuted experimental designs and their application in conjoint analysis. Journal of Sensory Studies 25: 127-145.

13. Gabay G, Moskowitz HR, Silcher M, Galanter E (2017) New Novum Organum: Policy, perceptions and emotions in health, Pardes-Ann Harbor Academic Press.

\section{Citation:}

Gillie Gabay, Attila Gere and Howard Moskowitz (2019) Understanding Effective Web Messaging - The Case of Menopause. Integr Gyn Obstet J Volume 2(2): 1-16. 